\title{
«Künzli-Freud-Liege»: Reminiszenz an einen bekannten Schweizer Homöopathen
}

Peter Marko

Korrespondenz: Dr. med. Peter Marko Bruggwaldstrasse 39e CH-9009 St. Gallen

p.marko[at]bluewin.ch
Bald nach unserem Umzug nach St. Gallen am Ende des letzten Jahrhunderts besuchte uns ein ehemaliger Studienkollege. Mit Ehrfurcht zeigte er auf eines der Einfamilienhäuser, die an unser Blockhaus grenzen. Auf einer Tafel stand dort schlicht: Dr. Künzli, Homöopath. Ich hatte sie schon früher wahrgenommen, aber nicht weiter darauf geachtet. Der Kollege meinte, es sei sicher der Künzli, der ihm die Homöopathie beigebracht habe. Ein begnadeter Lehrer, der es verstanden habe, die Materie sehr lebendig und praxisnah zu erklären, ein feiner Mensch dazu. Er lebe leider nicht mehr.

Es schien mir keine üble Art, einen Arzt zu ehren, indem man sein Praxisschild am Haus liess. Ansonsten war ich von Dr. Künzli und seinem Haus nicht sehr beeindruckt, da ich von Kollege Furlenmeier in die Homöopathie eingeweiht worden war, der ähnliche fachliche und menschliche Qualitäten besessen hatte. Ich bedauerte ein wenig, dass ich weder neben dem einen noch dem anderen gewohnt hatte. Denn wie die Forschung auf diesem Gebiet zeigt, verbreiten sich in sozialen Netzwerken Einstellungen und Eigenschaften, zum Beispiel Übergewicht, gewissermassen «von selbst». Nachbarn beeinflussen sich, vielleicht sogar während des Schlafes. Was Homöopathie betrifft, sind wir also zu spät nach St. Gallen umgezogen, weil solche Übertragungen vermutlich mit dem Tod aufhören, auch wenn es manche verneinen. und gewünscht hatte: ein grosses Zimmer mit einem Lavabo und einem separaten WC.

Am besten gefiel mir eine Liege aus dunkelbraunem Holz, bedeckt mit einem gemusterten feinen Teppich. Sie war fast gleich wie die Liege, die Freud in seiner Praxis hatte, die man an der Bergstrasse 19 in Wien besichtigen kann.

Die Tochter hatte nichts gegen mein Ansinnen. Sie räumte aber ein, die Mutter, die nicht mehr im Hause lebte, müsse es noch bewilligen. Ich stellte mir schon vor, wie ich die Patienten auf der Liege untersuchen und behandeln würde, und so war ich sehr enttäuscht und betrübt, als ich nach ein paar Tagen einen negativen Bescheid bekam. Ich fragte, ob ich mindestens die Liege kaufen könne. Die Mutter schlug mir auch diesen Wunsch ab. Die Liege stamme noch vom Urgrossvater und sei ein Erinnerungsstück an die drei Generationen der Künzli-Ärzte.

Das Haus, das ich jeden Tag sah, verkörperte für mich seither eine ziemlich hohe Zahl unerfüllter Wünsche, die sich in meinem Leben angesammelt hatten. Schweren Herzens fand ich andere Räume und eine gebrauchte, schlichte, nichtssagende, übliche Metalliege dazu.

Es vergingen ein paar Jahre. Eines Abends rief mich Frau Künzli Junior an und fragte, ob ich die Liege noch immer haben wolle. Selbstverständlich, antwortete ich sofort. Wie viel sie denn dafür haben

\section{Es schien mir keine üble Art, einen Arzt zu ehren, indem man sein Praxisschild am Haus liess.}

Hätte ich die Scharen der Patienten gesehen, die in die Praxis von Dr. Künzli geströmt waren ...

Nach nicht zu langer Zeit hatte ich genug von Praxisvertretungen und beschloss, wieder eine, was Tätigkeitsspektrum und Zeitaufwand betrifft, beschränkte Alterspraxis zu führen. Was war naheliegender, als dies in der ehemaligen Praxis von Dr. Künzli zu tun? Nach mehreren vergeblichen Anrufen gelang es mir eines Abends, die Tochter von Dr. Künzli zu erreichen. Ich erklärte ihr, was ich im Sinn hatte, und durfte die Räume anschauen, was mich schon sehr zuversichtlich stimmte. Ich war begeistert, als ich genau das sah, was ich mir vorgestellt möchte? Nichts, sie seien froh, wenn ich sie nähme, da sie das Haus renovieren würden, und die Liege ihnen nur im Weg stehe.

Die Liege war nicht nur massiv (der Hauptgrund, warum sie die mehr als hundert Jahre in gutem $\mathrm{Zu}$ stand überlebt hatte), sondern auch schwer. Die Schubladen waren voller Instrumente und jahrzehntealter Medikamente. Man sah, dass der letzte Dr. Künzli kein strenger Homöopath gewesen war, sondern ein Arzt, der wenn nötig auch allopathische Mittel einsetzte.

Mit Mühe und trotz der kalten Jahreszeit in Schweiss gebadet, verfrachteten meine Frau und ich 


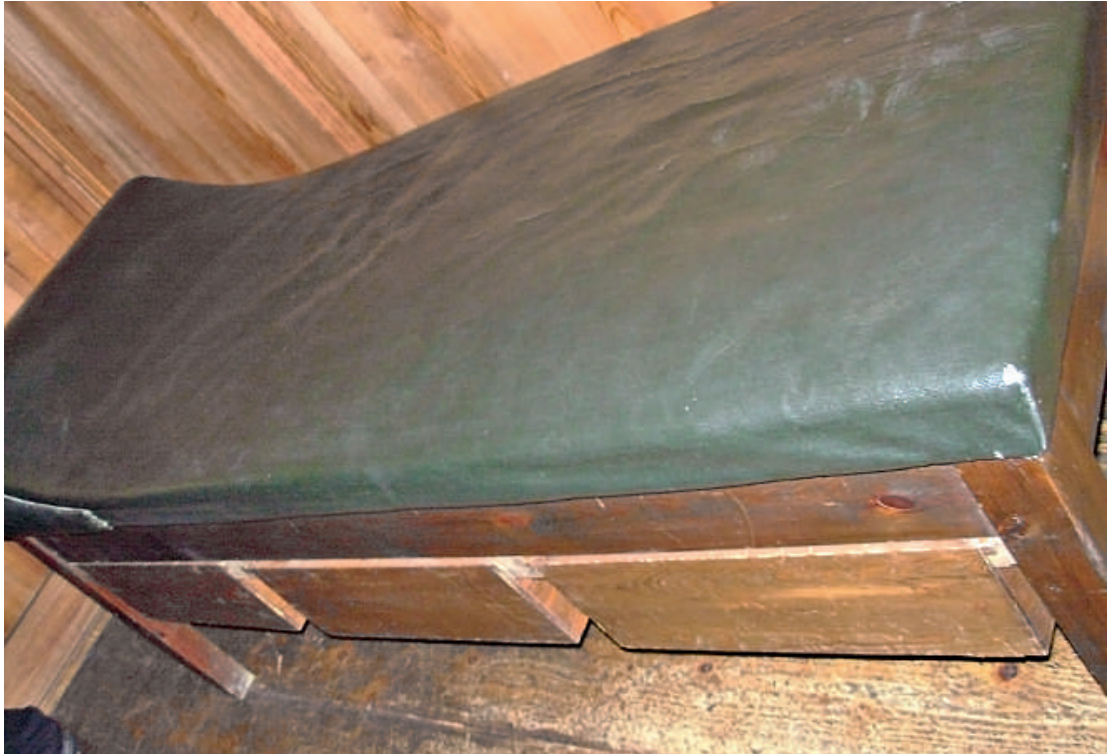

Das Vermächtnis des Homöopathen: die «Künzli-Freud-Liege».

die Liege und separat die vollen Schubladen auf einen gemieteten Lastwagen und nachher von dort mit Hilfe eines Nachbarn in unsere Praxis. Sie roch etwas nach dem lange ungebrauchten Raum, in dem sie wie Dornröschen geweilt hatte, bis wir sie befreiten.

In dem gutfrequentierten Raum und mit den geöffneten leeren Schubladen verlor die Liege den Geruch, und so konnten wir sie bei Bedarf auch wie- interessante Geschichte der drei Generationen der Künzli-Ärzte wurde uns von der Mutter über die Tochter nachgeliefert. So trug die Liege auch zum Familienbewusstsein unserer Nachbarn bei.

Wir hatten Freude an diesem schönen Möbelstück. Nicht selten machte ich während der Mittagspause auf der Liege ein erquickliches Schläfchen, und wenn ich auf die Patienten wartete, streckte ich meine Glieder darauf aus. Ich hoffte, mindestens in dieser Beziehung Freud und den Künzlis ähnlich zu sein.

Dann war endgültig Schluss mit der Praxistätigkeit. Was sollte mit der Liege, diesem Prachtstück, geschehen? Zuerst bot ich sie den Kollegen aus dem Qualitätszirkel an. Alle waren mit Liegen versorgt, niemand wollte mein Juwel - sicher nur, weil sie es nicht kannten. Dann schrieb ich das Medizinhistorische Museum in Zürich an. Es zeigte auch kein Interesse, vermutlich aus demselben Grund, da ich ein Bild der Liege beizulegen versäumt hatte. Ich erhielt aus Zürich aber den Hinweis, das Historische Museum in St. Gallen würde sich vielleicht für die Liege interessieren.

Dieser Tipp war ein Volltreffer. In St. Gallen war nämlich just eine Ausstellung über die Geschichte der Medizin in dieser alten, geschichtsträchtigen Stadt in Vorbereitung. Sicherheitshalber kam zuerst die Kuratorin bei uns vorbei, um die Liege in Augenschein zu nehmen. Sie meinte sofort, das Stück sehe aus wie die Freud-Liege, auch wenn sie jetzt, ohne den alten Teppich, irgendwie nackt dastand. Kurz danach kam sie

\section{Nicht selten machte ich während der Mittagspause auf der Liege ein erquickliches Schläfchen (...). Ich hoffte, mindestens in dieser Beziehung Freud und den Künzlis ähnlich zu sein.}

der für Patienten benützen. Manche merkten nichts, manche fragten, wo wir dieses Museumsstück, überzogen mit dem bereits hundert Jahre alten, dunkelgrünen Leder, aufgestöbert hätten. Gerne erzählten wir, dass sie noch von Grossvater Künzli stamme, der nicht weit im Kanton Appenzell Ausserrhoden in der Zeit um die vorletzte Jahrhundertwende eine Praxis geführt und hoch zu Ross die Patienten besucht hätte. Dank den Fortschritten der Medizin begannen die Ärzte damals Patienten vermehrt in Praxisräumen zu behandeln und brauchten neu neben einem Wartezimmer auch eine Liege im Behandlungsraum. Die mit einer Hilfe und einem grösseren Wagen, um die Liege abzuholen.

Eigentlich hätte ich keinen besseren Zeitpunkt wählen können, um meine Praxistätigkeit zu beenden.

Die Liege ist neben anderen sehenswerten Exponaten im Rahmen der Ausstellung «Zeit für die Medizin! Einblicke in die St. Galler Medizingeschichte» noch bis 20. Mai 2012 im Historischen und Völkerkundemuseum St.Gallen zu bewundern. 